Aristóteles Mesquita de Lima Netto

Cíntia de Sousa Carvalho

Diego Oliveira Ribeiro

Eleno Marques de Araujo

Elisângela Maura Catarino

Evandro Salvador Alves de Oliveira

José Tiago das Neves Neto

Juliana Silva Guabiroba

Marcelo Máximo Purificação

Rogério Machado Pereira

Organizadores

\title{
O DESAFIO MULTIDISCIPLINAR
}

$1^{\mathrm{a}}$ Edição Eletrônica

Uberlândia / Minas Gerais

Navegando Publicações

2020

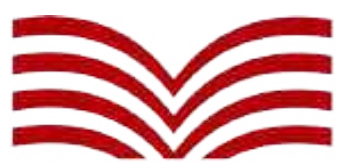

NAVEGANDO 


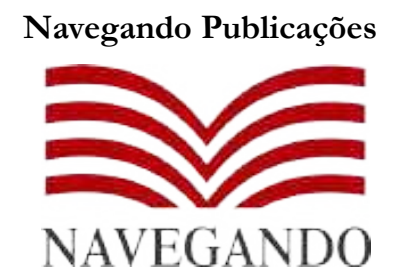

www.editoranavegando.com

editoranavegando@gmail.com

Uberlândia - MG,

Brasil

\section{Copyright $(\odot)$ by autor, 2020.}

O112 - Lima Netto, Aristóteles Mesquita de et al. (Orgs.). O desafio multidisciplinar. Uberlândia: Navegando Publicações, 2020.

ISBN: 978-65-81417-11-6

d. $10.29388 / 978-65-81417-11-6-0$

Vários Autores

1. Educação. 2. Multidisciplinaridade. II. Navegando Publicações. Título.

$$
\begin{gathered}
\mathrm{CDD}-370 \\
\mathrm{CDU}-37
\end{gathered}
$$

Revisão: Jonathan Emanuel Paulo de Oliveira / Lurdes Lucena Designer Capa: Alberto Ponte Preta

Foto Capa: Aristóteles Mesquita de Lima Netto

Local: Fazenda Rioverdinho da Barra Grande - Outubro 2019.

Diagramação: Alberto Ponte Preta

\section{Índice para catálogo sistemático}

Educação $\quad 370$ 


\section{SUMÁRIO}

PREFÁCIO

Guilherme Sousa Borges

EFICÁCIA DE FUNGICIDAS NO CONTROLE DA FERRUGEM

ASIÁTICA DA SOJA NO MUNICÍPIO DE MINEIROS-GO

Michele Gouveia Mendonça de Sousa - Ricardo Pereira de Sousa - Rogério

Machado Pereira

EXPLORANDO O PROCESSO ASSEGURAR A ENTREGA DE

BENEFÍCIOS DE TI DO COBIT 5.0: ELEMENTOS NECESSÁRIOS

Danilo Marques Oliveira - Aguinaldo Aragon Fernandes - Emilia da Costa

Garcia

INTERVENÇÃO PEDAGÓGICA E METODOLOGIA ATIVA: O USO

DA PBL NA DISCIPLINA DE ESTATÍSTICA

Danilo Marques Oliveira - Rosemara Perpétua Lopes - Emília da Costa

Garcia

A LEI DE “CHICO NÃO É DE FRANCISCO”: O RACISMO INSTITUCIONAL PRESENTE NO COMBATE AO TRABALHO INFANTIL

Lousana de Jesus Santana - Marcelo Máximo Purificação

PAULO FREIRE E ANÍSIO TEIXEIRA: POSSIBILIDADES DE NE-

GOCIAÇÕES ENTRE CURRÍCULO E GESTÃO

Éderson Andrade - Graziela Zambão Abdian

ATRIBUTOS FÍSICOS DE UM NEOSSOLO QUARTZARÊNICO EM

DIFERENTES SISTEMAS DE USO E MANEJO NO SUDOESTE

GOIANO

Gabriela Maria Kuss - Diego Oliveira Ribeiro - Lásara Isabella Oliveira Lima

Gustavo Castoldi - Warlles Domingos Xavier

FORMAÇÃO PEDAGÓGICA DE PROFISSIONAIS BACHARÉIS EM AGRONOMIA E SUA AÇÃO DOCENTE NO ENSINO SUPERIOR

Diego Oliveira Ribeiro - Zaqueu Henrique de Souza - José Humberto

Rodrigues dos Anjos - Gustavo Castoldi

O SUJEITO E SUA SINGULARIDADE: ENTRE AS DIMENSÕES OBJETIVAS E SUBJETIVAS DA VIDA CONTEMPORÂNEA

Aristóteles Mesquita de Lima Netto - Carolina Silva Naves

A TEORIA DAS REPRESENTAÇÕES SOCIAIS EM MOSCOVICI E SUA CONTRIBUIÇÃO PARA A EDUCAÇÃO INFANTIL

Milian Daniane Mendes Ivo Silva 
INFÂNCIA E EDUCAÇÃO INFANTIL: CONTRIBUIÇÕES DA TEO-

RIA HISTÓRICO-CULTURAL PARA COMPREENDER O DESENVOLVIMENTO INFANTIL

Milian Daniane Mendes Ivo Silva

PEDAGOGIA: REFLEXÕES SOBRE A TRANSVERSALIDADE DA 117 DIDÁTICA, FORMAÇÃO DO EDUCADOR, PESQUISA E APRENDIZAGEM SIGNIFICATIVA NO CURRÍCULO DE MARKETING Samuel Pedro Gonzaga - Eleno Marques de Araújo - Wellington Jhonner D. Barbosa da Silva

VISÃO ORGÂNICA DA TERAPIA CENTRADA NO CLIENTE Adilson Dutra de Souza - Eleno Marques de Araújo - Vânia Maria de Oliveira Vieira

PESQUISA DE ALTERAÇÕES OCULARES EM CÃES COM INFECÇÃO EXPERIMENTAL POR LEPTOSPIRA INTERROGANS SOROVARIEDADE CANICOLA

Michelle Brich - Fernanda Senter Magajevski - Eric Mateus Nascimento de Paula - Carolina de Alvarenga Cruz - Fernanda Cassioli Moraes - Daniel Bartoli de Sousa - Raphaella Barbosa Meirelles Bartoli

ABORDAGEM CLÍNICA E EPIDEMIOLÓGICA DOS PRINCIPAIS ASPECTOS DA PERITONITE INFECCIOSA FELINA

Yasmine Azarias Faria Lima - Carolina de Alvarenga Cruz - Raphaella Barbosa Meirelles Bartoli - Eric Mateus Nascimento de Paula

LEISHMANIOSE VISCERAL NO ESTADO DE GOIÁS, BRASIL, NO PERÍODO DE 2001 A 2015: UMA ANÁLISE DA DISTRIBUIÇÃO ESPACIAL EM RELAÇÃO A MALHA RODOVIÁRIA, TEMPERATURAS, ÍNDICES PLUVIOMÉTRICOS E CIDADES TURÍSTICAS

Eric Mateus Nascimento de Paula - Carolina de Alvarenga Cruz - Raphaella Barbosa Meirelles Bartoli - Ivanilton José de Oliveira - Sandra Maria Alkmin Oliveira

SUSTENTABILIDADE EM SISTEMAS INTEGRADOS DE PRODUÇÃO AGROPECUÁRIA

Jaison dos Santos - Adriana Rodolfo da Costa - Patrícia Costa Silva - Kássia de Paula Barbosa - Franciele de Freitas Silva

DESVENDANDO A SEXUALIDADE: UMA ANÁLISE A PARTIR DA EDUCAÇÃO SEXUAL

Amanda de Oliveira Valeiro - Aristóteles Mesquita de Lima Netto

EDUCAÇÃO, CONHECIMENTO, CULTURA E MOVIMENTO HUMANO: UM RETORNO AOS TERMOS E SENTIDOS Antônio Camilo Cunba - Evandro Salvador Oliveira 


\title{
EDUCAÇÃO, CONHECIMENTO, CULTURA E MOVIMENTO HUMANO: UM RETORNO AOS TERMOS E SENTIDOS*
}

\author{
Antônio Camilo Cunha ${ }^{1}$ \\ Evandro Salvador Alves de Oliveira ${ }^{2}$
}

\section{Introdução}

Para conhecermos e termos consciência de algo, muitas vezes é necessário voltar aos termos, voltar à origem. É o que vamos tentar fazer com esta reflexão. Pretendemos, pois, voltar à educação, ao conhecimento e à cultura fazendo uma síntese dessas dimensões e depois colocá-las no campo do movimento humano. Trata-se de retornar (um eterno retorno) ao conhecimento desses esteios existenciais, como forma de impulso e tomada de consciência de quão importantes são neste contemporâneo e de tamanha liquidez.

Sobre cada uma destas dimensões (dimensões tão dinâmicas e abertas) existe muita literatura e reflexão. Vamos aqui, tão só, fazer uma sistematização de enquadramento. Julgamos relevante o pensamento de Morin (2001), o pai da teoria da complexidade, particularmente quando o autor refere que a educação, por exemplo, deve ser um despertar para a filosofia, para a literatura, para a música, para as artes. É isso que preenche a vida. Esse é o seu verdadeiro papel. Diríamos também que a educação, o conhecimento e a cultura fazem parte e constituem outro fenômeno que é o movimento humano.

É a partir de alguns retornos no tempo e na história, com reflexões teóricas acerca do universo que envolve a educação, o conhecimento e cultura, que as análises aqui são voltadas. Nessa construção teórica consideramos o tempo da complexidade em que vivemos, bem como as mudanças que ocorrem na sociedade e os aspectos políticos, econômicos, culturais, entre outros, que a envolve. São reflexões e elucidações que vêm à tona a partir de vivências e ex-

\footnotetext{
${ }^{*}$ doi - 10.29388/978-65-81417-11-6-f.219-228

${ }^{1}$ Instituto de Educação da Universidade do Minho. CIEC - Centro de Investigação em Estudos da Criança (Uminho). Doutor em Estudos da Criança pela Universidade do Minho (Portugal). Email: camilo@ie.uminho

${ }^{2}$ UNIFIMES - Centro Universitário de Mineiros. CIEC - Centro de Investigação em Estudos da Criança (Uminho). Doutorando em Estudos da Criança pela Universidade do Minho (Portugal). Doutor em Educação pela Universidade de Uberaba - UNIUBE - E-mail: evandro@unifimes.edu.br
} 
periências com a profissão docente em seu pleno exercício, construídas ao longo de jornadas consideráveis no campo da educação.

\section{Voltar à educação}

Se há área tão escrutinada e complexa é por certo a educação. Se há área tão rica em posições teórico-práticas, conceções, paradigmas é a educação (BERTRAND; VALOIS, 1996; MORIN, 1995, 2001, 2002; ABBAGNANO, 2007A; ADORNO, 1995).

A educação como potência, cultura, palavra, número, ética, política, economia, cidadania, caminhada espiritual, humanidade, ir para a frente, ir para diante, são algumas das reflexões que os autores nos fornecem. Na retaguarda desses sentidos está a ideia de que só com a educação é possível ao homem romper com a sua animalidade - assente nos instintos, nas emoções básicas - e transformar-se num Ser Humano. Serão estes os caminhos que levarão o homem na procura e na ação de uma Vida Boa, que se quer plena e feliz.

Sem termos a possibilidade de fazermos uma análise exaustiva sobre o que é a educação, vamos, aqui, tentar fazer uma síntese desse conceito. Assim, podemos partir do pressuposto de que o fenômeno "educação" aparece como alicerce da condição humana, que através do seu pensamento e ação conduzem o homem na procura de uma vida boa, melhor, com maiores possibilidades. Enquanto em algumas sociedades o acesso à educação, "educar-se na escola", parece ser apenas um protocolo a ser cumprido ao longo da vida e da formação humana - sem causar muitos efeitos -, em outras, essa mesma "educação" é aquela que possibilita ao sujeito ter condições de viver dignamente e por meio dela sustentar uma família, etc.

A educação como pilar da construção do Ser Humano - formação do Espírito Humano - tem, talvez possamos dizer assim, um sentido original e ao mesmo tempo uma grande amplitude de significação. Por um lado, temos um sentido original. Quando retornamos a etimologia da palavra vemos que Educação é associada ao latim, Educare - trazer de fora para dentro, e Educere - enquanto movimento de elevar ou conduzir, para fora de, para fora do indivíduo, aquilo que ele tem dentro de si - a sua humanidade. Por outro, encontramos uma amplitude e significação enquanto fenômeno que se aplica aos humanos, tomando como centralidade o indivíduo, o grupo, a família o social e agora o global; referindo-se também a uma intervenção ao longo da vida: passagem da infância à idade adulta, chegando aos senescentes, e agora, a preocupação da educação para a morte.

O sentido original da educação tal como a sua amplitude e significação, estão muito bem retratados em particular no campo da história e filosofia da educação, onde podemos encontrar autores, correntes, conceitos que abordam as representações sobre o que é a educação, o que é educar, a importância da educação, entre outros. Em todo esse sentido histórico e filosófico destacamos 
conceitos como: aretê, paideia, razão, estética, ética, billdung, espírito, democracia, potencialidades, valores, nobreza, comportamentos, competências, atitudes, capacidade crítica, liberdade, consciência, cultura, política, ciência, conhecimento, cidadania, entre outros.

A educação é assim, um percurso - interno e externo; formal, informal e não-formal; objetiva e subjetiva - caracterizado pela participação ativa e crítica do educando e do educador. Ora, esta tarefa é da responsabilidade de toda a sociedade - "para educar uma criança é preciso toda uma aldeia" - em particular da família e da escola (CAMILO CUNHA; GONÇALVES, 2015, p.37).

Percebemos que o movimento humano tem em si, traz em si e convoca para si, dinâmicas educativas. Provavelmente seja por isso que a educação pelo movimento, principalmente após os estudos de Le Boulch $(1988 ; 1987)$ no campo da Educação Física, iniciados na década de 70, 80, tenha ganhado espaço nas discussões acadêmicas, considerando a escola (desde a educação de crianças pequenas) um importante espaço para o desenvolvimento dessas dinâmicas educativas advindas do universo Educação.

\section{Voltar ao conhecimento}

O conhecimento constitui-se como uma forma de ser distintiva da condição humana assente e manifestada em ideia (s) - pensamento, razão (PLATÃO, KANT, 1998, 1989; ADORNO; HORKHEIMER, 1985); espírito (HEGEL, 1991, 2002) e materialidade (ARISTÓTELES, 1998; MARX, 1990). Vamos constatar que existem muitos olhares (teorias) sobre o conhecimento. Numa taxonomia simples quando falamos em conhecimento estamos a falar em dois sentidos.

Epistemologia ou teoria do conhecimento científico - como conhecimento racional e que daí resulta um saber, um conhecimento racional elaborado a partir da observação, do raciocínio ou da experimentação (método científico) dando origem à ideia de ciência (HESSEN, 1980; ABBAGNANO, 2007b). Vai ser assim um conhecimento que se opõe à opinião, ao conhecimento imediato, à doxa (senso comum).

Nesse sentido, o objetivo da ciência é descobrir e formular leis (teorias), mas também produzir materiais (técnica, instrumentos). A Epistemologia tradicionalmente assenta em dois olhares estruturantes: um olhar empirista que diz que o conhecimento deve ser baseado na experiência (mundo vivido, experienciado, empírico) e olhar racionalista, que diz que a Fonte do conhecimento se encontra na razão, e não na experiência, na crítica e na reflexão. Na junção destes dois olhares ainda podemos encontrar um sentido idealista na procura de um conhecimento Universal.

Foucault $(1986,1989)$ nos esclarece que a epistemologia designa o modo particular de como se articula o saber de uma época - coerência interior. Vai referir-se à Epistemologia do Renascimento que vai caraterizar-se pelo conceito 
de semelhança - analogia entre as coisas; e à epistemologia da Modernidade que por sua vez vai caraterizar-se pelas identidades e diferenças. Quando se passa de uma epistemologia para a seguinte há um fenômeno de ruptura - mas que não esquece as objetividades e "subjetividades" anteriores.

Assim, a epistemologia tem a ciência como objeto, o que é diferente da filosofia da ciência - que faz uma reflexão lógica, rigorosa sobre os instrumentos, metodologias e resultados do conhecimento científico. A epistemologia estuda de modo crítico os princípios, as hipóteses gerais, as conclusões das diferentes ciências para lhes apreciar o valor e o alcance objetivo. A epistemologia não esquece a história das ciências - paradigmas, acumulação, caducidade, rupturas, leis, novos problemas e novas hipóteses. Hoje o conhecimento científico (epistemologia) tem alargado a sua influência - financiamento, economia, política, entre outros aspectos. Sob outro ponto de vista tem a Gnosiologia como uma teoria Geral (Origem) do Conhecimento. Como teoria crítica do conhecimento que incide sobre a origem, formas e limites - tende para todas as formas de conhecimento. É o percurso que Kant (1989) faz na sua Crítica da Razão Pura. Fazendo o elogio ao conhecimento científico (epistemologia), não deixa de referir outras formas de conhecimento - gnosiologia - pensamento, experiência, ciência, metafísica, gnosiologia, razão, fé. Também gostaríamos de referir a outras duas dimensões tão importantes no tocante ao conhecimento: i) a fenomenologia, que para além de um método é uma forma de conhecimento. Um conhecimento/manifestação autêntico(a) - as "coisas mesmas" (BRENTANO, 1995; HURSSEL, 1986; SARTRE, 2007; MERLEAUPONTY, 1999; LEVINAS, 1993, 1998, 2000) e a ii) a hermenêutica como caminho metodológico de interpretação da realidade, textos e contextos sociais (STEIN, 1996; HEIDEGGER, 2000, 2003; GADAMER, 1998; RICOEUR, 1997, 1999, HABERMAS, 1987).

Apesar de não ser consensual a separação entre fenômenologia e hermenêutica (por um lado vemos que se interligam, por outro que são "coisas" diferentes), consideramos esta taxonomia como valorativa na análise do movimento humano. A epistemologia como um conhecimento específico resultado do método científico; a Gnosiologia como uma teoria onde cabem todas as outras formas de conhecimento e seus contextos históricos, culturais e sociais; a fenomenologia e a hermenêutica como origem e interpretação.

Já o movimento humano, este se configura como uma forma de conhecimento que podemos apresentar (uma síntese) da seguinte forma. Primeiramente a partir de um conhecimento que se apoia no conhecimento científico (ciência e suas diferentes áreas) - conhecimento, natureza do conhecimento e seus limites. É neste contexto que surge a epistemologia (teoria do conhecimento que convoca a lógica, a metafísica, e diz a filosofia da ciência). A epistemologia estuda a origem, a estrutura, os métodos e a validade do conhecimento - científico assente na objetividade dos factos que encontramos no movimento humano. 
Em segundo plano temos um conhecimento que se apoia no conhecimento da teoria geral do conhecimento ou gnosiologia. De fato, o movimento humano pode ser investigado do ponto de vista científico (positivista/ciências naturais) mas também o seu conhecimento centra-se numa teoria geral do conhecimento (onde se encontram as ciências sociais e do comportamento) - observamos, por exemplo, as brincadeiras e jogos tradicionais, que mais do que uma análise (conhecimento) conseguido pelas hipóteses e metodologias científicas, elas devem ser analisadas pelas hipóteses e metodologias existenciais, fenomenológicas, hermenêuticas, onde o inusitado, o subjetivo, o interpretativo e o intersubjetivo estão presentes.

O conhecimento que o Movimento Humano procura é parcial, mas também global e incluso. O conhecimento não é apenas científico (seria muito redutor se assim fosse - apesar de muitos profissionais e investigadores desta área assim não o achar), mas é também de um saber global, onde a ciência, a cultura, o corpo, o movimento objetivo e subjetivo, a tradição e as particularidades estão presentes. O Movimento Humano é desses dois campos/paradigmas.

\section{Voltar à cultura}

Clifford Geertz, o renomado fundador da antropologia interpretativa, ao publicar pontos e contrapontos sobre cultura, deixou para trás apontamos antes feitos a partir de uma visão com as lentes da antropologia estrutural, momento em que passou a investir em uma nova teoria antropológica. Nessa nova perspectiva, a cultura deixa de possuir uma concepção singular e a expressão "culturas" passa a ganhar espaço e outras compreensões.

Cultura, em linhas gerais é compreendida como o conjunto de tradições, técnicas e instituições que caraterizam um grupo humano, pois a cultura assim entendida é normativa e adquirida pelo indivíduo desde a infância através dos processos de aculturação. A maioria dos sociólogos, antropólogos, etnólogos, partilham a opinião de Rousseau, sobre o papel da cultura - só existe ser humano por acumulação e produção de elementos culturais, pela aquisição intelectual, literária, artística. E caso não o seja, a natureza humana fica assente na condição animal/biológica, tornando-a menos humana. Sousa (2017) diz que a cultura alimenta a ideia de civilização. Nesse sentido, a ideia de cultura toma também outras concepções: cultura de massa, cultura de classe, cultura midiática, cultura popular, cultura acadêmica, cultura científica, identidade cultural, etc.

A ideia (palavra) cultura traz-nos assim um manancial de reflexões e taxonomias que são convocadas em várias áreas do saber. Fala-se em cultura, multiculturalismo, interculturalismo, transculturalismo (CAMILO CUNHA, 2014). Peguemos na definição mais simples, a que Alfred Krober (1993) e a de Manuel Patrício (1996) abordam. A cultura é aquilo que o homem acrescente à 
natureza (sua natureza ontológica, biológica, antropologa), pela sua capacidade criadora e transformadora. A cultura eleva-nos, assim, acima da nossa condição animal. A cultura torna-nos mais completos e inovadores pela capacidade de dar significado. Torna-nos (dizemos nós) mais "largos", profundos, mais "leves", ricos e desejavelmente melhores - não necessariamente melhores. A cultura é um caminho de excelência para atingir a liberdade. Um homem culto tem apontado a si duas setas: uma para a razão, outra para o coração - que fará dele um sábio. No entanto, também gostaríamos de ressaltar que existe(m) cultura(s), que pode(m) não ser boa(s).

Vejamos, por exemplo, o caso das culturas que não promovem ideais de humanização e com elas ideais de estética e ética. Uma outra definição pode ser encontrada na ideia de cultura como o complexo que envolve o conhecimento, arte, crenças, leis, práticas, costumes, significados, hábitos adquiridos e transmitidos pelo homem, enquanto ser individual e social. No entanto, esta definição parece-nos ser um pouco redutora, linear, materialista, externa e ideológica - contribuindo para a emergência de povos/culturas ditas primitivas e desenvolvidas (científicas) e assim, a abertura de portas para a injustiça social e cultural. Por outro lado, o olhar sociológico e antropológico trouxe novas concepções destacando-se o homem culturalmente igual - mesmos deveres, direitos, potencialidades; e culturalmente diferente - capacidades, competências, manifestações que dizem o seu ser onto-cultural. A cultura é agora uma manifestação interna, humanizada, dinâmica capaz de criar existência - existência social, econômica, política, simbólica, religiosa, intelectual, artística (CHAUÍ, 2000; 2002).

O movimento humano enquanto expressão cultural reserva cultura (memória, tradição) e ao mesmo tempo produz cultura, o novo, a criação, o futuro. Quando pensamos que existe um entrecruzamento entre educação, conhecimento e cultura, em que o movimento humano ocorre em meio a esses processos, registramos uma pergunta: no tempo da complexidade, da aceleração e profusão de tecnologias digitais, como se efetiva a produção desses fenômenos que temos nos debruçado até então?

\section{Educação, conhecimento e cultura no tempo da complexidade}

A evolução técnica, tecnológica, a ciência, a informação, a cibernética, os sistemas (micro, meso, macro), a globalização, entre outros meios do capitalismo global, fez com que o homem tomasse consciência que a vida (sociedade) e o mundo estão envoltos numa complexidade. Estes fatos acabam por influenciar o entendimento e as novas práticas educativas, culturais e de conhecimento. Um dos autores de referência que começou a refletir sobre esse fenômeno foi Morin (1995; 2000a; 2000b; 2001) com a conhecida teoria da complexidade referindo que tudo se liga a tudo, bem como tudo tem a ver com tudo - tecido/sistema único e inseparável que também recebe o nome de "complexus". 
Este "novo mundo" apontado por Morin parece trazer (recuperar) uma visão monista e contrária à tradição cartesiana (dualista - separada). Começa por sustentar que a complexidade antes de ser um dado externo, ela é intrínseca e fundadora da realidade. Apesar de ao longo da história da filosofia e da ciência a complexidade não ter um olhar favorável - lembremo-nos que a filosofia e a ciência preferiam a unidade, a generalização única (não se familiarizavam com a desordem, a incerteza, a confusão), a complexidade - como um dado evidente - carece-nos de um olhar mais sistematizado e rigoroso. No entanto, não deixa de ser objeto de reflexões (por ventura teorias) que tentam dar sentido a essa mesma complexidade e que tentam abrir um inteligível e revelar as subjetividades, intersubjetividades e mesmo o inexplicável. É um campo que não deixa de trazer novas perguntas, novos diálogos, novos cenários empíricos/imanentes, lógicos, racionais, espirituais, simbólicos e transcendentes. Há um confluir de todas as formas de conhecimento: mítica, religiosa, científica, eliminando a explicação linear, disjuntiva, redutiva, fragmentada, elegendo o diálogo, a recursividade, o holograma. Lê-se e interpreta-se a tradição, a cultura, as racionalizações do pensamento procurando nelas as ligações complexas.

O Movimento Humano, na esteira dessas reflexões, também não deixa de ser pensado, operacionalizado sob a ótica da complexidade, pois este é o sentido atual que temos vivido na pós-modernidade.

\section{Algumas Considerações}

A ideia de ruminação, lançada no resumo deste trabalho, se articula muito com a sugestão anunciada no título - retornar aos termos e sentidos. Ferraz (2016) é quem propõe uma obra repleta de reflexões, ou melhor, ruminações. Ao discorrer sobre cultura letrada e dispersão hiperconectada, a autora se apropria da analogia ruminação para nos chamar a atenção sobre a importância do processo de digerir as informações, o conhecimento.

$\mathrm{Na}$ sociedade da informação, da velocidade, do ritmo acelerado de trabalho, de frágeis relações sociais e muitos outros fenômenos, sujeitos não possuem tempo para ruminar aquilo que é posto, de modo a entender a cultura do letramento, das palavras, em razão do aumento da dispersão que ocorre por causa do contato ininterrupto com as tecnologias. Pensar nos termos que a educação, cultura, conhecimento e movimento humano carregam exigem constantes processos de ruminação, de ir e vir, tomar e retomar, para, por conseguinte, compreender e estabelecer novas relações, educar e construir conhecimento no mundo.

\section{Referências}

ABBAGNANO, N. Educação. Dicionário de Filosofia. São Paulo: Martins Fontes, 2007a. p. 357-358. 
. Teoria do conhecimento. Dicionário de Filosofia. São Paulo: Martins Fontes, 2007b. p. 213-215.

ADORNO, T. Educação e emancipação. Petrópolis: Vozes, 1995.

ADORNO, T.; HORKHEIMER, M. Dialética do esclarecimento. Rio de Janeiro: Zahar, 1985.

ARISTÓTELES. Política. Lisboa: Veja, 1998.

BERTRAND, Y.; VALOIS, P. Paradigmas Educacionais - Escola e Sociedade. Lisboa: Instituto Piaget, 1996.

BRENTANO, F. Psychology from an Empirical Standpoint. London: Routledge, 1995.

CAMILO CUNHA, A. Multiculturalismo e educação. Da diversidade: crítica/crítica. Santo Tirso: Whitebooks, 2014.

CAMILO CUNHA, A.; GONÇALVES, S. A criança e o brincar como obra de arte: Analogias e sentidos. Santo Tirso: Whitebooks, 2015.

CHAUÍ, M. Convite à Filosofia. São Paulo: Edições Atica, 2000.

Experiência do Pensamento. Ensaios sobre a obra de Merleau Ponty. São Paulo: Martins Fontes, 2002.

FERRAZ, M. C. F. Ruminações: cultura letrada e dispersão hiperconectada. Rio de Janeiro: Garamond, 2015.

FOUCAULT, M. Microfísica do poder. Rio de Janeiro: edições Graal, 1986.

Vigiar e punir. Petrópolis: Editora Vozes, 1989.

GEERTZ, C. A Interpretação das Culturas. Rio de Janeiro: LTC,1989.

HABERMAS, J. Dialética e Hermenêutica. Porto Alegre: L\&PM, 1987.

HESSEN, J. Teoria do Conhecimento. Coimbra: Arménio Amado - Editor, 1980.

HEIDEGGER, M. Problemas Fundamentais de la Fenomenologia. Calesa, 2000.

Caminho da Linguagem. Petrópolis: Vozes Editores, 2003.

HEGEL, G. Sistema da Vida Ética. Lisboa: Edições 70, 1991.

Fenomenologia do Espírito.Vozes Editores, 2002.

HUSSERL, E. A Ideia de Fenomenologia. Textos Filosóficos. Lisboa: Edições 70, 1986.

LE BOULCH, J. O Desenvolvimento Psicomotor do nascimento até 6 anos: a psicocinética na idade pré-escolar. Porto Alegre: Artes Médicas, 1988. 
Rumo a uma ciência do movimento humano. Porto Alegre: Artes Médicas, 1987.

MARX, K. Capital (Tomo 1). Lisboa: Edições Avante, 1990. . Manuscritos Económico - Filosóficos. Lisboa: Edições 70, 1990.

MERLEAU-PONTY, M. Fenomenologia da Percepção. São Paulo: Martins Fontes, 1999.

MORIN, E. Introdução ao pensamento complexo. Lisboa: Instituto Piaget, 1995.

Ciência com consciência. Rio de Janeiro: Bertrand Brasil, 2000ª .

. A inteligência da complexidade. São Paulo: Petrópolis, 2000b.

. A religação dos saberes: o desafio do século XXI. Rio de Janeiro:

Bertrand Brasil, 2001.

get, 2002.

Os Sete saberes para a educação do futuro. Lisboa: Instituto Pia-

GADAMER, H.-G. Verdade e Método. Rio de Janeiro: Editora Vozes, 1998.

LEVINAS, E. Totalidade e infinito. Lisboa: Edições 70, 2000.

. Ética e Infinito. Lisboa: Edições 70, 1998.

. Humanismo do outro homem. Petrópolis: Vozes, 1993.

PATRÍCIO, M. A escola cultural: Horizonte decisivo da reforma educativa. 3. ed. Lisboa: Texto Editora, 1996.

PATRÍCIO, M.; SEBASTIÃO, L. Conhecimento do Mundo e da Vida. Passos para uma Pedagogia da Sageza. Lisboa: Universidade Aberta, 2004.

PLATÃO. Fédon. Lisboa: Veja, 1970.

KANT, E. Crítica da Razão Pura. Lisboa: Fundação Kalouste de Gulbenkien, 1970.

Moeda, 1998.

Crítica da Faculdade de Juízo. Lisboa: Imprensa Nacional Casa da

. Crítica da Razão Pura. Lisboa: Edições 70, 1989.

KROEBER, A. A natureza da cultura. Lisboa: Edições 70, 1993.

RICOEUR, P. Interpretação e ideologia. Rio de Janeiro: Francisco Alves, 1977.

Do texto à ação. Lisboa: Rés, 1999. 
SARTRE, J.-P. O ser e o nada - Ensaio de ontologia fenomenológica. Tradução de Paulo Perdigão. 15. ed. Petrópolis: Vozes, 2007.

STEIN, E. Aproximações sobre hermenêutica. Porto Alegre: Edipucrs, 1996.

SOUSA, J.M. Cultura, E-Dicionário de Termos Literários (EDTL), coord. de Carlos Ceia, Disponível em: <http://www.edtl.com.pt>. Acesso em: 29 jan. 2017. 